\title{
O ensino na área da saúde e sua repercussão na qualidade de vida docente
}

\author{
Teaching in the Health Professions and its Impact \\ on Teachers' Quality of Life
}

\author{
Maria Regina Silvério ${ }^{\mathrm{I}}$ \\ Zuleica Maria Patrício ${ }^{\mathrm{I}}$ \\ Ingrid May Brodbeck ${ }^{\mathrm{I}}$ \\ Suely Grosseman ${ }^{\text {II }}$
}

PALABRAS CLAVE

- Qualidade de Vida

- Saúde do Trabalhador.

- Ensino

- Docente

- Promoção da Saúde

- Atenção à Saúde
Recebido em: 21/11/2008 Reencaminhado em: 30/04/2009 Aprovado em: 21/06/2009 $65 \frac{\text { REVISTA BRASILEIRA DE EDUCAÇÃO MÉDICA }}{34(1): 65-73 ; 2010}$ 65 34(1): $65-73: 2010$

\begin{abstract}
R E S U M O
Pesquisa de abordagem qualitativa, realizada numa universidade de Santa Catarina, com o objetivo de conhecer a repercussão do processo de ensino-aprendizagem na qualidade de vida e saúde de docentes de cursos de graduação da área da saúde. Os dados foram coletados por entrevista em profundidade e analisados pela técnica de análise de conteúdo, associada ao processo de análise-reflexão-síntese. Observou-se que diferentes fatores promovem ou limitam a qualidade de vida do docente, inclusive para além do espaço laboral. Esses fatores estão relacionados à dinâmica das diversas interações pessoais desenvolvidas nos contextos dos processos de ensino-aprendizagem, especialmente naqueles onde há atividades com a população. Outros fatores envolvem questões relacionadas a problemas da instituição, interação com gestores, condições de trabalho e remuneração. O processo de ensino-aprendizagem na área da saúde aparece, ao mesmo tempo, como fonte de sofrimento e de prazer. O desafio dos docentes que cuidam enquanto ensinam é continuar a potencializar o autocuidado e os espaços de interação social com vistas à promoção de um ambiente coletivo saudável.
\end{abstract}

\section{A B S T R A C T}

This qualitative study carried out in a university in the State of Santa Catarina, Brazil, aimed to analyze the impact of the teaching-learning process in the quality of life and health conditions of faculty members from health area graduation courses. Data were collected through in-depth interviews and submitted to content analysis, associated to the analysis-reflection-synthesis process. It was observed that different factors either facilitate or limit the quality of life of the faculty members, including issues outside the workplace itself. Such factors are related to the dynamics of personal interactions developed in the teaching-learning process, especially those involving activities with the user population. Other factors were related to institutional problems, the interaction with administrators, working conditions, and the wage. The teaching-learning process in the health area appears, at the same time, as a source of distress and of pleasure. The challenge for teachers that care while teaching is to continue enhancing self-care and to ensure social interaction opportunities in order to promote a healthy collective environment.

\footnotetext{
${ }^{I}$ Universidade do Sul de Santa Catarina, Tubarão, SC, Brasil.

II Universidade Federal de Santa Catarina, Florianópolis, SC, Brasil.
} 


\section{INTRODUÇÃO}

A ideia de pesquisar o tema qualidade de vida no ambiente universitário foi mobilizada ao longo de muitos anos de observação do cotidiano das práticas docentes nesse contexto. Aanálise reflexiva desses dados, associada à escuta de depoimentos repetitivos de professores da área da saúde, assinalou haver importantes repercussões do trabalho docente na qualidade de vida dessa população a ponto de gerar problemas de saúde.

As discussões atuais sobre saúde no Brasil têm dirigido a atenção de cientistas e gestores dessa área para a amplitude do conceito saúde e a necessidade da intersetorialidade. A Política Nacional de Promoção à Saúde ${ }^{1}$ mostra bem essa dimensão, a ponto de esta estratégia hoje ser considerada um novo paradigma para as políticas públicas. Nesse contexto, um dos conceitos mais presentes é o de "qualidade de vida".

Para Seidl e Zannon ${ }^{2}$, o conceito de qualidade de vida é relativamente recente e decorre, em parte, dos novos paradigmas que têm influenciado as políticas e as práticas do setor saúde nas últimas décadas. A incorporação da qualidade de vida nas questões de saúde tem acompanhado a compreensão que se tem hoje sobre a complexidade do processo saúde-doença, haja vista a identificação da multiplicidade de fatores envolvidos.

Nesse modelo, segundo Patrício ${ }^{3}$, o potencial saúde-doença tem sido analisado considerando a qualidade de vida nos aspectos ambientais, culturais, econômicos e existenciais que envolvem as pessoas em seus diversificados processos de interação como indivíduo particular e coletivo. Por essa perspectiva, os dados precisam, também, se originar de escutas de percepções das pessoas e de observações sistemáticas dos estilos de vida e das condições que a população tem para atender suas necessidades em diversos contextos.

Além de textos referentes às políticas públicas de saúde, várias fontes demonstram a importância de associar a qualidade de vida à saúde, como, por exemplo, Fleck et al. ${ }^{4}$, Minayo et al. ${ }^{5}$, Patrício ${ }^{6,7}$, Seidl e Zannon ${ }^{2}$. Nesse universo, alguns estudos apontam o mundo do trabalho como um fator determinante na qualidade de vida e saúde humana ${ }^{8-13}$.

Em estudos que abordam o trabalho docente, como, por exemplo, Lemos ${ }^{14}$, Lopes ${ }^{15}$, Martins e Robazzi ${ }^{16}$, Pereira e $\mathrm{Arno}^{17}$, Rocha e Felli ${ }^{18}$, percebe-se uma variedade de fatores relacionados ao processo de ensino-aprendizagem que podem interferir na qualidade de vida e saúde dos professores. Assim como evidenciado nesta pesquisa, esses fatores estão relacionados a situações geradas nos microcontextos das interações e também na relação do docente com a instituição universidade.
A pesquisa desenvolvida por Pereira e Arno ${ }^{17}$ com professores da Universidade Federal do Rio de Janeiro sobre a qualidade de vida no trabalho universitário e o bem-estar com a vida em geral aponta que a satisfação do docente com seu trabalho tem ligação com as relações interpessoais no convívio acadêmico, social e cultural com os alunos e com os demais professores.

Considerando esse contexto e que, segundo a literatura, o trabalho docente tem sido ainda pouco estudado ${ }^{19,20}$, decidiu-se fazer uma pesquisa de abordagem qualitativa com o objetivo de conhecer a repercussão do processo de ensino-aprendizagem (PEA) na qualidade de vida e saúde de docentes, mais especificamente de profissionais da área da saúde de uma universidade de Santa Catarina.

Espera-se que esse estudo possa estimular a realização de pesquisas dessa natureza em outros contextos e mobilizar reflexões críticas que possibilitem movimentos de aperfeiçoamento dos processos de trabalho de docentes da área da saúde, especialmente tendo em vista o potencial do ambiente acadêmico para tornar-se espaço de promoção da saúde.

\section{MÉTODO}

O estudo foi realizado numa universidade de Santa Catarina de caráter comunitário, sem fins lucrativos, com abordagem qualitativa, tendo como base Bogdan e Biklen ${ }^{21}$, Lüdke e André $^{22}$, Minayo ${ }^{23}$, Patrício ${ }^{3,7}$ e Strauss e Corbin ${ }^{24}$.

Os participantes foram docentes de cursos de graduação da área da saúde e de áreas afins, cujos processos de ensino-aprendizagem (PEA) incluíam atividades com a população em contextos de serviços de atenção à saúde. Foi estabelecido como critério de inclusão que o docente estivesse desenvolvendo essa atividade naquela instituição há pelo menos dois anos, com carga horária mínima de 12 horas semanais.

A amostra foi constituída por três docentes de Medicina, Enfermagem, Fisioterapia, Odontologia, Farmácia, Psicologia e Serviço Social, totalizando 27 participantes. Eles foram selecionados aleatoriamente, por sorteio, a partir da lista de docentes obtida nas respectivas coordenações de curso. Docentes dos cursos de Nutrição e Educação Física não foram incluídos por não preencherem todos os critérios de inclusão.

A técnica utilizada na coleta de dados foi a entrevista em profundidade, com apoio num formulário composto por questões semiestruturadas relacionadas a fatores do ambiente universitário que influenciavam o desenvolvimento do PEA e a relação deles com a qualidade de vida e saúde dos docentes. As entrevistas foram realizadas por duplas de pesquisadores (um docente e um aluno de graduação), em vários ambientes da universidade e em 
serviços de saúde onde estavam sendo realizadas atividades de ensino com a população. Para validação do instrumento foi realizado estudo piloto com um docente de cada curso que não fazia parte da amostra.

A análise dos dados foi realizada durante todo o processo de coleta de dados, utilizando-se a técnica de análise de conteúdo, com codificação e identificação de categorias, associada ao processo de análise-reflexão-síntese, com vistas à identificação de temas emergentes ${ }^{7,24,25}$.

O projeto da pesquisa foi aprovado pelo Comitê de Ética da universidade, com protocolo de número 04046406-III, e seguiu todos os preceitos éticos definidos na Resolução 196/196.

\section{RESULTADOS}

Na concepção dos docentes, ter uma boa qualidade de vida significa "gostar da vida"; "levar a vida com tranquilidade"; "ter paz de espírito"; "ser feliz"; "ter saúde"; "estar em equilíbrio", "sentir-se realizado, satisfeito e de bem consigo mesmo e com os outros".

Entendem que para isso é necessário "desenvolver" interações sociais saudáveis com vizinhos e colegas de trabalho; "ter tempo" para realizar atividades e para "viver ao lado da família"; e "manter hábitos saudáveis", como comer e dormir bem. Implica, também, ter alguns bens materiais, como casa própria, transporte particular, trabalho e salário adequados para sustento tranquilo, morar com conforto e adquirir plano de saúde e outros bens.

A análise dos depoimentos dos participantes evidenciou a existência de variadas situações construídas no processo de trabalho docente, as quais têm consonância com suas representações de qualidade de vida. Tais situações se relacionam com o ambiente organizacional como um todo e, mais intensamente, com as interações cotidianas nos microcontextos do processo de ensino-aprendizagem, que compreendem as relações entre docentes, alunos, população e coordenação de curso.

O processo de ensino-aprendizagem promove a qualidade de vida quando a interação professor-aluno causa "felicidade", traduzida pelos docentes como: "prazerosa"; "tranquila", "harmoniosa" e "construtiva". O processo sempre é positivo quando existe "gosto de trabalhar com alunos" e quando suas atividades "estimulam uma troca enriquecedora".

Na relação professor-aluno-população, a promoção da qualidade de vida ocorre pelos mesmos motivos: quando a interação provoca prazer e felicidade, e quando não há intercorrências no ambiente que prejudiquem a atenção às pessoas com quem estão trabalhando.
Há docentes que expressam mais especificamente o porquê da satisfação que têm com as atividades de ensino-aprendizagem com a população. São motivos relacionados a questões existenciais individuais ou coletivas, tais como: aumenta "a vontade de viver", "o ânimo", "a esperança" e "a coragem"; "enriquece e é construtiva na medida em que envolve trabalhar com jovens e com a cura da população". Para alguns, é ainda "mais gratificante quando a população demonstra satisfação com o processo de ensino-aprendizagem".

O trabalho com pessoas mais jovens foi um fator de destaque na promoção da qualidade de vida de alguns docentes. Para eles, a interação com o aluno é muito importante, pois, no processo de ensinar e aprender, há muita troca e, em razão de o jovem ser "cheio de vida", isso contribui "para a gente reavivar formas de ser, pensar e agir".

Da mesma forma, a interação com a população também é "incentivo para viver", em especial quando naqueles processos há a cura da dor do paciente: "É motivador, principalmente para os alunos, e isso causa satisfação no professor".

Na relação com a coordenação do curso, a qualidade de vida do docente é promovida quando as situações de ensino-aprendizagem encaminhadas, particularmente as que envolvem alunos, recebem a "atenção" do coordenador e sua demonstração de "disponibilidade", "flexibilidade" e "liderança" na resolução das questões. Esse fenômeno ocorre, especialmente, quando o coordenador não se deixa envolver por "queixas" e "fofocas" dos alunos e considera os princípios éticos e a especificidade pedagógica que envolve a situação.

O trabalho na instituição tem propiciado a evolução do docente no âmbito não apenas profissional, mas também pessoal, por aumentar a rede de interações e fortalecer os laços afetivos com a família e com outras pessoas de convívio social. Desta forma, ainda, para alguns docentes, a qualidade de vida tem melhorado não só pelo "prazer" e pelas "alegrias" nas interações com alunos, mas também pela "satisfação" com as "realizações pessoais" decorrentes do trabalho, por estarem fazendo o que gostam e/ou pela renda obtida com o mesmo.

Ressalta-se a satisfação apontada com as interações afetivas entre docente-aluno e docente-docente, construídas nos microcontextos do ambiente acadêmico, e também com o próprio objeto do trabalho docente, mesmo sob condições conflituosas.

Vários depoimentos demonstraram haver uma consciência coletiva sobre este aspecto, como, por exemplo: "Apesar de muitos dissabores e sobrecarga de trabalho, você ainda vê o brilho nos olhos de quem está perto da gente". Isto, para eles, torna-se ainda mais importante quando os alunos demonstram satisfa- 
ção com o trabalho que realizam, como ilustra o seguinte depoimento: "Tenho orgulho de sair na rua e dizer que estudo nesta universidade".

Foram identificadas, também, várias situações do PEA que representam limitações na qualidade de vida dos docentes e que geram "estresse", "muita ansiedade" e "perda de sono". Das situações identificadas, destacam-se as que provocam conflitos nas interações aluno-professor, aluno-coordenação e aluno-aluno.

Esses conflitos ocorrem quando há: "displicência e intransigência por parte do aluno"; "atitudes antiéticas do aluno junto à população, ao professor e à coordenação do curso"; "competitividade entre alunos que geram agressões"; "falta de comunicação saudável entre alunos"; "formação de grupos corporativos entre alunos", incluindo aqueles com "pacto de mediocridade".

Entendem por pacto de mediocridade as situações em que grupos de alunos se unem para articular meios que os favoreçam em detrimento da qualidade do processo de ensino-aprendizagem, seja em relação a uma questão particular ou a um processo mais amplo.

Os conflitos identificados como aqueles que mais limitam a qualidade de vida dos docentes dizem respeito aos dilemas éticos provocados por alunos que envolvem o professor em situações constrangedoras junto à coordenação do curso e à ouvidoria da universidade.

Nesse âmbito, salientam que há coordenadores de curso que, ao interagirem com alunos, geram atitudes agressivas nestes. Por sua vez, estes alunos reagem de forma a contagiar toda a turma a ponto de prejudicar o andamento de todas as atividades didáticas. Alguns docentes referem que esse tipo de postura costuma gerar "um clima muito pesado", e há casos cuja gravidade prejudica o bem viver, a ponto de "provocar a perda do sono e muita ansiedade".

Há situações envolvendo relações afetivas mais intensas do professor com o aluno que causam muito desconforto, com repercussão negativa na qualidade de vida docente. Entre estas, foram citadas aquelas em que o docente tem que lidar com "reprovação de alunos" ou quando é obrigado a fazer o papel de "mediador" ou "conselheiro" em assuntos delicados trazidos pelos alunos, especialmente os de ordem da vida particular.

Os docentes apontam também grande comprometimento na qualidade de vida pelo "excesso de horas de trabalho", pois todas as horas são alocadas para atividades com o aluno, o que se agrava quando há "excesso de alunos em grupos de estágio", "insuficiente material de apoio" para algumas atividades pedagógicas e "falta de transporte para os diversos locais de estágio".
Agrande responsabilidade que os docentes têm com a qualidade das intervenções dos alunos junto à população também gera "muita preocupação". Segundo depoimentos, nesse contexto, "muitas vezes, o docente perde o controle das ações dos alunos". Tudo isso gera grande "esforço físico e mental", aumentando a "carga de estresse", especialmente nos docentes de Enfermagem e Medicina.

Além do estresse relacionado às particularidades dos processos de ensino-aprendizagem em saúde, os participantes desse estudo sofrem pela instabilidade gerada na organização por problemas econômicos advindos do mercado que se instalou no ensino superior do País. Os próprios docentes justificam esse fenômeno como algo não localizado, posto que outras instituições de ensino, da mesma natureza, têm perdido alunos para as faculdades que, por não terem o caráter de universidade - custos com investimento em pesquisa e cursos de pós-graduação stricto sensu -, oferecem mensalidades de menor valor.

Há docentes que consideram a possibilidade de participar mais desta problemática e contribuir com estratégias de superação junto à instituição. Mas entendem que isto só seria possível se não houvesse "tanta distância" entre suas percepções e aquelas da reitoria sobre as questões acadêmicas.

Nesse contexto, a grande queixa dos docentes é a falta de "escuta" por parte da reitoria, a qual, segundo depoimentos, costuma fazer encaminhamentos e tomar decisões com base apenas nas percepções de seus gestores diretos.

Para a maioria dos docentes, todo esse processo de viver laboral tem prejudicado a sua qualidade de vida como um todo, porque eles não conseguem superar o estresse no próprio ambiente da instituição. Nesse sentido, é comum extrapolarem para o domicílio e demais ambientes sociais sentimentos de ansiedade, tristeza e preocupação.

A "falta de tempo" no cotidiano da vida docente foi apontada como um fator estressante a ponto de interferir na qualidade de vida como um todo, seja por dificuldades pessoais de administrar "esse tempo", seja pelo volume e complexidade das exigências acadêmicas inerentes ao processo do trabalho docente, que extrapolam em mais de $100 \%$ a carga horária alocada no contrato.

A maioria costuma trabalhar em casa, fomentando ainda mais o estresse. Esse fenômeno se expressa cotidianamente pela "falta de convivência com a família e amigos", por conta das atividades docentes que precisam "levar para fazer em casa" e a insatisfação pelo "baixo salário" considerando as horas trabalhadas e o acúmulo de responsabilidades e enfrentamento de situações estressantes que envolvem alunos e população. 
O baixo salário e a insegurança de manutenção do emprego, segundo os docentes, têm obrigado alguns colegas a "buscar outras fontes de renda", o que acaba por aumentar o estresse. Essa situação aumenta a possibilidade de "descarrego em casa", ou seja, atitudes de catarse com a família que não seria possível expressar no ambiente institucional.

Esse estilo de vida, construído pelo professor no trabalho e que extrapola o espaço laboral, tem repercutido na sua qualidade de vida e saúde em geral. Grande parte dos docentes afirma que o estresse desenvolvido nesse cotidiano os torna "frágeis", "irritados" e "angustiados". Apontam como fatores agravantes dessa situação "o não atendimento adequado das suas necessidades de sono e repouso", o "constante cansaço mental" e a "fadiga geral" que vivem cotidianamente.

No contexto estudado, não há evidência de existirem movimentos de criação de espaços que possam promover sensações de bem-estar. Talvez por isto tenha ocorrido a seguinte representação coletiva dos participantes desse estudo: "Lugar de trabalho é lugar de vida, e aqui é só trabalho!". Esta representação foi significativamente identificada em seus discursos.

Os professores consideram que trabalhar com pessoas é muito desgastante para a saúde, seja pelo estresse provocado pelas interações diretas com os alunos e a população assistida, seja pelas demais interações no contexto institucional, especialmente aquelas que determinam atitudes que contrariam seus princípios e disponibilidades. Eles próprios têm consciência de que essas situações provocam "baixa imunidade" e repercussões nas suas condições de saúde geral, favorecendo estados "gripais constantes", "enxaquecas", "labirintites", "crises hipertensivas", "estados depressivos" e "problemas dermatológicos", entre outros.

Para alguns desses docentes, essa situação é agravada pelo estresse causado por não conseguirem se cuidar. Mesmo sendo profissionais da área da saúde, não conseguem desenvolver práticas saudáveis de prevenção e nem dar atenção específica aos agravos já evidentes. Justificam essa atitude do "não cuidar de si" pela demanda de tarefas e pela intensidade do envolvimento que desenvolvem com o trabalho docente em saúde e com a instituição.

Outros, cientes da necessidade de prevenção de problemas, apesar de vivenciarem situações estressantes, afirmam que "não adoecem" porque adotam atitudes de "autocuidado", como: fazer "ioga"; praticar "atividades físicas"; promover momentos de "lazer com a família"; fazer "exames preventivos"; usar sistematicamente "vitaminas e estimulantes"; procurar "fazer o que gosta"; manter "bom astral" e "respeitar direitos e deveres da cidadania" do contexto universitário.
Há, ainda, docentes que referem não sofrer por questões laborais e que procuram encarar "naturalmente" questões do cotidiano que, para outros colegas, costumam "ser estressantes". Consideram que "tudo depende de como a pessoa enfrenta as situações". Alguns destes docentes mostraram que esse fenômeno representa estratégias de sobrevivência utilizadas para evitar ou amenizar situações estressantes, como, por exemplo, "conseguir se desligar do trabalho" e "não se envolver".

\section{DISCUSSÃO}

A análise das situações de insatisfação e desconforto identificadas neste estudo, com base na literatura, nos leva a sugerir que grande número dos docentes tem potencial para desenvolver processos de adoecimento, inclusive a Síndrome de Burnout, bastante comum no trabalho docente e de cuidadores, posto que a prática do ensino integra características particulares que são fontes de problemas físicos e psíquicos ${ }^{26,14,27,28}$.

Considere-se também que a prática docente investigada, especialmente a dos professores de Medicina e de Enfermagem, é duplamente sujeita a situações de desgaste. Primeiro, pela quantidade de carga horária que o docente costuma cumprir em processos de ensino-aprendizagem que envolvem atividades de saúde junto à população; segundo, porque esses processos costumam exigir que o professor desenvolva o papel de cuidador enquanto ensina: cuida do aluno e cuida da população que participa do processo de ensinar-aprender.

Essa função gera ainda maior estresse pela responsabilidade que tem com a segurança dos alunos e da população atendida. Isto exige do docente uma atitude de presença constante e comprometida, especialmente em situações complexas e de alto risco, o que aumenta a exigência de trabalho e a possibilidade de estresse.

Fernández, apud Domiguez ${ }^{29}$, reforça essa questão quando afirma existir um estresse relacional específico entre profissionais que têm contato direto e continuado com outras pessoas, como ocorre com os docentes. O estudo de Souza ${ }^{30}$, realizado com docentes do ensino médio da rede pública do Rio de Janeiro, reforça a importância do aspecto relacional para a promoção da saúde dos docentes.

As condições de trabalho que no estudo foram apontadas como limitadoras da promoção da qualidade de vida não diferem muito das encontradas em outras pesquisas. Lemos ${ }^{14}$, analisando estudos de vários autores, mostra que as condições de trabalho dos docentes brasileiros são consideradas precárias e têm sido apontadas como causadoras do adoecimento (físico e psíquico). Araújo et al. ${ }^{31}$, ao estudarem o estresse ocupacional em professores da Universidade Estadual de Feira de Santana, na Bahia, encontraram o adoecimento psíquico com prevalência de $19,1 \%$ naqueles trabalhadores. 
Esses estudos têm contribuído para apontar e ressaltar os fatores que afetam a qualidade de vida dos docentes, pontuando, por exemplo, que:

a não (ou des)valorização e não reconhecimento do trabalho docente, [...], as condições salariais [...], a necessidade de ampliação da jornada de trabalho para recompor salário, os aumentos expressivos de alunos em sala de aula, além da luta permanente por manter-se no emprego, tudo isso tem contribuído para perda de qualidade da saúde dos professores ${ }^{31}$.

Para Araujo et $\mathrm{al}^{31}$, os constrangimentos relacionados à organização do trabalho encontrados no estudo são referidos como as maiores fontes de incômodo, especialmente a desproporcionalidade salarial e as responsabilidades assumidas, o estado de conservação de materiais e equipamentos, e a exposição a riscos de contaminação.

Adescoberta de fatores que causam estresse na população de docentes remete a outra categoria importante, também identificada no estudo: a "falta de tempo". Este foi um fator apontado como limitante para a qualidade de vida. O estudo de Lopes ${ }^{15}$ com professores da Universidade Estadual do Rio de Janeiro também destaca o "tempo" como aspecto fundamental e presente no cotidiano do trabalho docente. Segundo a autora, nessa população, o tempo do trabalho e o tempo fora do trabalho se confundem e "mais do que isto, esse tempo de trabalho é intenso, multifacetado e atravessado por atividades e exigências diversas que não cessam, nem em época de greve, tampouco nas férias" ${ }^{\prime 15}$.

Tal como na pesquisa aqui descrita, Lopes ${ }^{15}$ mostra que o processo de lidar com o tempo também causa estresse, pela constante ansiedade e até angústia, posto que no trabalho docente "sempre há alguma atividade para ser feita fora da universidade", o que exige do profissional "tirar" do tempo destinado ao seu lazer e descanso horas para suas atividades acadêmicas.

Outro aspecto importante, revelado no contexto estudado, diz respeito ao significado que tem o trabalho da docência para os professores, manifestado por sentimentos de satisfação e insatisfação e pelas repercussões na qualidade de vida e saúde.

Em pesquisa realizada com docentes enfermeiras da Universidade Estadual de Londrina, no Paraná, sobre a temática prazer e sofrimento no trabalho, Martins e Robazi ${ }^{16}$, apesar de não terem realizado a associação com os significados de ser docente, identificaram nos discursos das profissionais mais sentimentos de prazer que de sofrimento pelo trabalho que desenvolvem.

A diversidade de expressões encontrada nos docentes da universidade em estudo demonstra a particularidade e também o sentido coletivo do significado do trabalho da docência e, por consequência, suas manifestações de sofrimento e de prazer, e as constantes expressões que mesclavam esses dois sentimentos.

Conforme Brant e Gomes ${ }^{26}$ :

é importante reconhecer que o sofrimento não tem uma manifestação única para todos os indivíduos de uma mesma família, cultura ou período histórico. O que é sofrimento para um não é, necessariamente, para outro, mesmo quando submetidos às mesmas condições ambientais adversas. [...] Resta ainda lembrar que no sofrimento é possível encontrar uma mesclagem de prazer e dor, simultaneamente(p.214).

O estudo de Fernandes ${ }^{32}$ com professores de ensino superior privado revelou que o fato de esses profissionais terem vocação e gostarem da profissão não impede que percebam seu cotidiano de trabalho também como "cansativo", "corrido", "apressado" e "estressante".

Ahmady et $\mathrm{al}^{19}$, em estudo com docentes de escolas médicas, identificaram alguns aspectos semelhantes aos aqui apresentados. Conforme o estudo, o nível de estresse encontrado naqueles docentes é significativo e tem sua fonte maior em conflitos originados de situações que envolvem o cumprimento de tarefas inerentes ao trabalho docente. Com base nessa complexidade, os pesquisadores apontam a importância de compreender as situações geradoras dos conflitos, com vistas ao desenvolvimento de estratégias institucionais que reduzam o nível de estresse nessa população.

Os resultados do presente estudo apontam também nessa direção, mas os significados atribuídos ao trabalho docente no contexto pesquisado indicam a necessidade de este ser compreendido na dialética prazer-desprazer.

Esse aspecto é sustentado por Breilh, apud Blallistreri e Víto$\mathrm{la}^{33}$, que afirma que o processo de trabalho não é, por si só, exclusivamente benéfico ou danoso à saúde. Seus aspectos benéficose destrutivos coexistem e atuam de forma distinta, conforme o momento histórico e o grupo social de referência.

A representação que Mauro, apud Rocha e Fellii ${ }^{18}$, faz ao definir o processo de ensinar como um "momento produtivo que gera tensões e satisfação pessoal", valida o significado do trabalho docente encontrado: se por um lado as dificuldades encontradas no trabalho constituem fatores desgastantes, por outro, "a satisfação em ensinar é potencializadora da qualidade de vida no trabalho"18.

\section{CONCLUSÕES}

A repercussão do processo de ensino-aprendizagem na qualidade de vida dos docentes universitários envolvem várias di- 
mensões, desde aspectos relacionados ao microcontexto da interação aluno-professor, até aqueles relativos a questões de gestão organizacional, remuneração e condições de trabalho, além de toda a gama de repercussões do trabalho acadêmico na vida extralaboral.

No entanto, o estudo revela que são as interações sociais, construídas nos diversos contextos do processo de ensino-aprendizagem e nas demais relações do cotidiano do ambiente universitário, que interferem de forma mais significativa, limitando e/ou promovendo a qualidade de vida e a saúde dos docentes.

As interações que limitam a qualidade de vida-saúde do docente envolvem situações de conflito entre aluno-aluno, aluno-professor e aluno-coordenação de curso. As interações que promovem a qualidade de vida-saúde dizem respeito àquelas entre professor-aluno e professor-aluno-população. Estas geram momentos de alegria, realização pessoal e profissional, troca de conhecimentos e afetividade. Também causam bem-estar aos docentes as demonstrações de respeito, satisfação e reconhecimento do seu trabalho por parte dos alunos e da população.

As responsabilidades constantes dos docentes, inerentes ao processo de ensino-aprendizagem em saúde, quando envolvem o aluno e a população, bem como as questões éticas associadas interferem sempre, limitando a qualidade de vida e provocando problemas de saúde quando não trabalhadas. Esse problema é ainda mais impactante devido à sobrecarga de trabalho imposta pelas atividades acadêmicas e que o docente é obrigado a levar para o ambiente extralaboral. Entretanto, são as atividades com os alunos e a população que também interferem, promovendo melhor qualidade de vida, pela gratificação expressa por ambos.

Os aspectos do contexto institucional que limitam a qualidade de vida docente poderiam ser amenizados pela simples incorporação de movimentos menos lineares na gestão organizacional, estimulando a participação coletiva e o diálogo.

A questão, também, é que o ambiente laboral acadêmico ainda não é percebido como espaço de promoção da qualidade de vida, apesar de que é em seu contexto que a maioria dos conhecimentos sobre essa temática é produzida.

Entretanto, o cenário encontrado neste estudo mostra que toda essa conjuntura, que configura o contexto universitário, não consegue abafar seu encanto. Essa realidade é reforçada por Lopes ${ }^{15}$ quando sustenta que:

[...] Ainda que a sensação de estar sempre correndo e deixando de fazer alguma coisa esteja continuamente presente; ainda que os projetos, as aulas, os artigos se- jam quase sempre preparados apressadamente [...] resta ainda um espaço na universidade que pulsa e produz vida (p.39).

Os dados do contexto do estudo apresentado revelam que há docentes que, apesar de constantemente vivenciarem situações de desconforto, mal-estar e até de adoecimento, percebem o seu trabalho como estímulo que dá sentido à vida. Para alguns, somente a condição de "ser professor" e de "estar na docência" já é motivo de promoção da sua qualidade de vida.

Os dados encontrados, somados aos trazidos pela literatura, podem sugerir uma imagem paradoxal do ambiente de trabalho universitário: ao mesmo tempo em que promove um espaço de potência para interações humanas, encontros e troca de conhecimentos, experiências, sentimentos e energias que contribuem para promover a qualidade de vida dos trabalhadores, também se mostra como um espaço sujeito a conflitos de várias naturezas a ponto de gerar situações constantes de estresse e de causar limitações à saúde integral.

O desafio dos docentes é buscar potencializar os espaços de interação com as pessoas que participam dos processos de ensino-aprendizagem, com vistas à promoção de um ambiente coletivo saudável, mesmo em situações de conflitos, e ao mesmo tempo desenvolver estratégias de autocuidado. Paralelamente, cabe à gestão universitária criar políticas que favoreçam estes espaços e promovam maior diálogo com os docentes com vistas ao desenvolvimento de ações que melhorem a qualidade de vida no ambiente universitário.

Nessa perspectiva, recomenda-se dar maior atenção aos docentes da área da saúde em virtude da particularidade de seus processos de trabalho. São muito variadas as atividades que esses docentes desempenham, em especial os que realizam atividades teórico-práticas diretamente com a população usuária dos serviços de saúde. A possibilidade de haver estresse é maior em razão das responsabilidades desses docentes nos processos que exigem a promoção da aprendizagem e o cuidado da vida do outro, representado pelo aluno e pelo usuário, temas que merecem mais estudos.

\section{REFERÊNCIAS}

1. Brasil. Ministério da Saúde. Política nacional de promoção da saúde. Brasília: Ministério da Saúde; 2006.

2. Seidl EMF, Zannon CMLC. Qualidade de vida e saúde: aspectos conceituais e metodológicos. Cad Saúde Pública. 2004;20(2)580-8.

3. Patrício ZM. Qualidade de vida do ser humano na perspectiva de novos paradigmas: possibilidades éticas e esté- 
ticas nas interações ser humano-natureza-cotidiano-sociedade. In: Patrício ZM, Casagrande JL, Araújo MF, orgs. Qualidade de vida do trabalhador: uma abordagem qualitativa do ser humano através de novos paradigmas. Florianópolis: PCA; 1999. p. 19-126.

4. Fleck MPA, Leal OF, Louzada S, Xavier M, Chachamovich E, Vieira G, et al. O instrumento de avaliação de qualidade de vida abreviado da Organização Mundial da Saúde (WHOQOL-bref): Aplicação da versão em português. Rev Saúde Pública 2000; 34(2)178-83.

5. Minayo MCS, Hartz, ZMA, Buss, PM. Qualidade de vida e saúde: um debate necessário. Ciênc Saúde Colet. 2000; 5(1):7-17.

6. Patrício ZM. O que seria importante pesquisar e como fazê-lo em favor da qualidade de vida? Texto Contexto Enferm. 1994;3(1):58-74.

7. Patrício ZM. A dimensão felicidade-prazer no processo de viver saudável: uma questão bioética numa abordagem holístico-ecológica. Florianópolis; 1995. Doutorado [Tese] - Universidade Federal de Santa Catarina.

8. Chanlat JF. O indivíduo na organização: dimensões esquecidas. São Paulo: Atlas, 1996.

9. Codo W, Sampaio, J. Indivíduo, trabalho e sofrimento: uma abordagem interdisciplinar. Petrópolis: Vozes, 1993.

10. Dejours, C. A loucura do trabalho. São Paulo: Cortez, 1992.

11. Oliveira RA, Ciampone MHT. A universidade como espaço promotor de qualidade de vida: vivências e expressões dos alunos de enfermagem. Texto Contexto - Enf 2006; 15(2)254-261.

12. Patrício ZM, Casagrande JL, Araújo MF, org. Qualidade de vida do trabalhador: uma abordagem qualitativa do ser humano através de novos paradigmas. Florianópolis: PCA, 1999.

13. Rodrigues MVC. Qualidade de vida no trabalho: evolução e análise no nível gerencial. Petrópolis: Vozes, 2002.

14. Lemos Lemos JC. Cargas psíquicas no trabalho e processos de saúde em professores universitários. Florianópolis; 2005. Doutorado [Tese] - Universidade Federal de Santa Catarina.

15. Lopes MCR. Universidade produtiva e trabalho docente flexibilizado. Est Pesq Psicol [periódico na Interent]. 2006 [acesso em 02 maio 2007];6(1): [aproximadamente 13p.]. Disponível em: http://www.revispsi.uerj.br/v6n1/artigos/PDF/v6n1a04.pdf.
16. Martins JT, Robazzi MLCC. Sentimentos de prazer e sofrimento de docentes na implantação de um currículo. Rev Gaúch Enferm. 2006; 27(2)284-90.

17. Pereira CA, Arno E. Um estudo da qualidade de vida universitária no trabalho entre docentes da UFRJ. Arq Bras Psicol. 1993;45(3/4):12-48.

18. Rocha SSL, Felli VEA. Qualidade de vida no trabalho docente de enfermagem. Rev Latino-am Enfermagem.2004;12(1):28-35.

19. Ahmady S, Changiz T, Masiello I, Brommels M. Organizational role stress among medical school faculty members in Iran: dealing with role conflict. BMC Med Educ. 2007;7(14):2-10.

20. Witter GP. Professor-estresse: análise de produção científica. Psicol Esc Educ. 2003;7(1):33-46.

21. Bogdan R, Biklen, S. Investigação qualitativa em educação. Porto: Porto; 1999.

22. Ludke M, André MDA. Pesquisa em educação: abordagens qualitativas. São Paulo: EPU; 1986.

23. Minayo MCS. O desafio do conhecimento: pesquisa qualitativa em saúde. $8^{\text {a }}$ ed. São Paulo: Hucitec; 2004.

24. Strauss A, Corbin J. Basics of qualitative research: grounded theory procedures and thecniques. California: Sage Publications; 1990.

25. Bardin L. Análise de conteúdo. Rio de Janeiro: Edições 70; 1991.

26. Brant LC, Gomes CM. A transformação do sofrimento em adoecimento: do nascimento da clínica à psicodinâmica do trabalho. Ciênc Saúde Colet. 2004; 9(1):213-23.

27. Reis EJFB, Araújo TM, Carvalho FM, Barbalho L, Silva MO. Docência e exaustão emocional. Educ Sociedade. 2004;27(94):229-53.

28. Tibúrcio A. A síndrome de Burnout em professores do ensino médio da rede pública estadual do município de Tubarão-SC. Tubarão; 2005. Mestrado [Dissertação] - Universidade do Sul de Santa Catarina.

29. Dominguez JA. Estrés en el profesorado universitário. Estudo piloto en dos centros de la Universidade de Huelva (España). Salud de los Trabajadore. 2004;12(2):5-25.

30. Sousa DL. Interação professor, aluno: que relações com a saúde? Rio de Janeiro; 2005. Mestrado [Dissertação] - Escola Nacional de Saúde Pública Sergio Arouca.

31. Araújo TM, Graça CC, Araújo, E. Estresse ocupacional e saúde: contribuições do modelo demanda controle. Ciênc Saúde Colet. 2003;8(4):991-1003. 
32. Fernandes MCSG. Escolha profissional e prática docente: $\mathrm{o}$ discurso de professores do ensino superior privado. Centro Universitário Moureira Lacerda GT: Didática, n.4. [on line]; 2007. [capturado 2 maio 2007]. Disponível em: http:/ / www.anped.org.br/reunioes/27/gt04/t046.pdf.

33. Ballistreri M, Vítola D. El processo de trabajo del docente universitário. Rev. Enf. Hosp. Ital. 2000;20(2):19-25.

\section{CONTRIBUIÇÃO DOS AUTORES}

Maria Regina Silvério, Zuleica Maria Patrício e Ingrid May Brodbeck participaram de todo o processo da pesquisa e da ela- boração do manuscrito; Suely Grosseman participou do processo de análise e redação final do manuscrito.

\section{CONFLITO DE INTERESSES}

Declarou não haver.

\section{ENDEREÇO PARA CORRESPONDÊNCIA}

Zuleica Maria Patrício

Rua das Araras, 396

Lagoa da Conceição - Florianópolis

CEP. 88062-075 SC

E-mail: zucamp@hotmail.com 